\title{
Cytotoxic Properties of Lyophilized Beers in a Malignant Cell Line
}

\author{
Carmela Spagnuolo*, Idolo Tedesco*, Maria Grazia Volpe, Stefania Bilotto, \\ Maria Russo, Gian Luigi Russo ${ }^{\#}$ \\ Institute of Food Sciences, National Research Council, Avellino, Italy. \\ Email: "glrusso@isa.cnr.it
}

Received November $26^{\text {th }}, 2013$; revised December $26^{\text {th }}$, 2013; accepted January $2^{\text {nd }}, 2014$

Copyright (c) 2014 Carmela Spagnuolo et al. This is an open access article distributed under the Creative Commons Attribution License, which permits unrestricted use, distribution, and reproduction in any medium, provided the original work is properly cited. In accordance of the Creative Commons Attribution License all Copyrights (C) 2014 are reserved for SCIRP and the owner of the intellectual property Carmela Spagnuolo et al. All Copyright (C) 2014 are guarded by law and by SCIRP as a guardian.

\begin{abstract}
Moderate beer consumption can be considered as part of a healthy diet since it may protect against heart disease, cancer and osteoporosis. The protective effects of beer reside in its polyphenol content whose chemical composition appears extremely complex. In the present study, five commercial beers with different polyphenol content (ranging between 690 - $2400 \mu \mathrm{M}$ equivalents of quercetin) were employed to investigate their cytotoxic effect in vitro on HL-60 cells derived from a human promyelocytic leukemia cell line. A significant reduction in cell viability was measured after 48 hours treatment. Lyophilized beers with higher polyphenol content showed the highest cytotoxicity compared to those with lower concentrations. However, when the assay was performed applying equal amounts of total polyphenols from different lyophilized beers, the sample possessing lowest amount of polyphenols (690 $\mu \mathrm{M}$ equivalents of quercetin) resulted the most effective in reducing cell viability. These data suggest that the biological activities of polyphenols present in beer are not simply dependent upon their total concentration, but qualitative profile and relative concentrations are even more important in determining their antiproliferative effects on cancer cells.
\end{abstract}

\section{KEYWORDS}

Beers; Cytotoxicity; Polyphenol; Flavonoids; HL-60

\section{Introduction}

The concept of chemoprevention is related to the use of pharmacological or natural products to counteract the progression of precancerous cells [1-3]. Many dietary components appear to act as potential chemopreventers. In fact, experimental evidence derived from laboratory and epidemiological studies suggest a possible inverse relationship between regular intake of vegetables, such as fruit and vegetables, and cancer development [3-5]. The beneficial effects of fruits and vegetables in the prevention of cancer are probably related to the presence of non-nutrient substances, generally defined as phytochemicals, with the relevant cytotoxic activity against cancer cells in preclinical models [6-8]. A mechanism is often

\footnotetext{
*Equal contribution.

${ }^{\#}$ Corresponding author.
}

evoked to explain the biological activity of phytochemicals referring to their antioxidant properties, although recent reports suggest the existence of alternative mechanisms involving their pro-oxidant activity $[9,10]$ and/or the capacity to trigger key factors regulating cell proliferation and cell death [3,11,12].

In addition to fruits and vegetables, non-alcoholic and alcoholic beverages, such as tea, red wines and beers contain phytochemicals possessing biological activities. Beer is produced by the saccharification of starch and fermentation of the resulting sugar. Most beers are flavored with hops, which add bitterness and act as a natural preservative. Beer is the world's most widely consumed alcoholic beverage and is the third-most popular drink overall, after water and tea $[13,14]$. Recently, it has been reviewed the role of a moderate consumption of beer against the occurrence of cardiovascular disease (CVD), 
hypertension, diabetes, and certain types of cancer, including colon, basal cell, ovarian, and prostate carcinoma, but to a lesser extent than wine intake, probably because of the lower phenolic content of beer [14,15]. However, a meta-analysis suggested that high consumption of beer and liquors may be associated with increased lung cancer risk, whereas modest wine consumption may be inversely associated with risk [16]. On the opposite, a different meta-analysis confirmed the J-shaped association between wine consumption and vascular risk and provided evidence for a similar relationship between beer and vascular risk [17]. More consistent are data obtained on animal models. As an example, beer intake prevented adryamicin-induced damage to mitochondrial chain components in Wistar male rats [18] and, in a pig model of myocardial infarction, beer intake was associated with lower oxidative stress, higher HDL-antioxidant capacity and improved global cardiac performance [19]. Similarly, intake of beer reduced the formation of colorectal tumors and preneoplastic lesions in azoxymethane-induced experimental carcinogenesis in male Fischer rats [20].

Data on the chemopreventive effects of hops and beer compounds (e.g., the prenylflavonoids: xanthohumol, isoxanthohumol and hop bitter acids exclusively present in beer compared to wine) on malignant cell lines have been extensively reviewed [14,21-23]. Dark beers possess the highest total phenolic and melanoidin content respect to alcohol-free beer [22], and the total antioxidant capacity of beer is strongly correlated with total polyphenol content [24]. Several evidences suggest a relevant biological role of hop-derived molecules, such as xanthohumol, isoxanthohumol and hop bitter acids. Xanthohumol is the most important and abundant prenylated flavonoids of the female inflorescences of the hop plant. During the brewing, $20 \%-30 \%$ of the molecule is converted in isoxanthohumol [25]. Xanthohumol have protective activity on several pathologies, such as cardiovascular diseases [26] and cancer [27]. The molecule induces a higher rate of apoptosis in glioblastoma cells than in normal astrocytes, which was associated with activation of p53 and an elevated $\mathrm{Bax} / \mathrm{Bcl}-2$ ratio in glioblastoma cells [28]. Furthermore, xanthohumol is known to be an effective inhibitor of cytochrome P450 enzymes and an inducer of $\mathrm{NAD}(\mathrm{P}) \mathrm{H}$ : quinone reductase $(\mathrm{QR})$ in HepG2 hepatoma cell line [29]. The molecule also increases tumour necrosis factor-induced apoptosis in leukemia and myeloma cells. This enhancement of cell death is correlated with down-regulation of nuclear factor-kappaB (NF- $\kappa \mathrm{B})$ survivin, Bcl-xL, XIAP, cIAP1, cIAP2, cylin D1, and c-myc [30]. Intraperitoneal treatment of xanthohumol, in doses ranging between 0.2 and $0.4 \mathrm{mg} / \mathrm{Kg}$ in rats with middle cerebral artery occlusion produced an evident reduction in infarct size compared to that in untreated animal control. This property is probably due to the inhibition of free radical formation and apoptosis, contributing to an improvement of the neurobehavior [31]. Regarding animal models of carcinogenesis, supplementation with isohumulones inhibited the formation of aberrant crypt foci with the concomitant decrease in prostaglandin E2 level in rat colon [32].

We previously demonstrated that a lyophilized preparation of beer with high phenolic content and antioxidant activity was cytotoxic with respect to a beer containing low polyphenols on HL-60 human leukemia cell line [24]. In the present study, we extended this initial observation analyzing five commercial beers characterized by different polyphenol content. We concluded that their cytotoxic effect on HL-60 cells was related to the specific profile of active compounds and their different origin, e.g., hops versus malts.

\section{Material and Methods}

\subsection{Chemicals}

Folin-Ciocalteau's phenol reagent (FCR), sodium carbonate, quercetin, neutral red, sodium chloride, dithiothreitol, and Triton X-100 were purchased from Sigma-Aldrich (Milan, Italy). RPMI medium, glutamine, penicillin, streptomycin, PBS (phosphate-buffered saline) tablets were purchased from Life Technologies (Monza, Italy). Fetal bovine serum (FBS) was from Lonza (Verviers, Belgium). All reagents used in this study were of pure, analytical grade.

\subsection{Beers Components and Preparation}

The beers tested in the present study have been the following: Samples 1 and 2 are obtained from pure lager malt, without hop and with low fermentation. The yeast employed is Saccaromices cerevisiae. Sample 3 is from melanoidin malt, with hop and highly fermented employing an "abbazia" yeast. Finally, Samples 4 and 5 are prepared with a mixture of malts and hops under low fermentation. Also in this case, the yeast employed is $S$. cerevisiae. All beers are filtered and pasteurized.

\subsection{Determination of Alcohol Content, Total Acidity, Volatile Acidity, Dry Matter and Ash}

Beers $(300-500 \mathrm{ml})$ were decanted in a $750 \mathrm{ml}$ flask, excess of carbon dioxide was removed by shaking. The beers were filtered through a dry filter paper by a covered funnel into a second flask. The shaking and filtering were repeated until the beers were completely degassed. The ethanol was separated by distillation. The density was measured at $20^{\circ} \mathrm{C}$ by a pycnometer, after making up the distillate to its original mass with water. Alcohol content is listed by volume. Total acidity was determined in a $100 \mathrm{ml}$ Erlenmeyer flask where $50 \mathrm{ml}$ of degassed 
beers were titrated with a $0.1 \mathrm{~N} \mathrm{NaOH}$ solution in the presence of phenolphthalein as the indicator, until the appearance of a pale pink color that should persist for 1 min. Calculate as $\mathrm{ml}$ of $0.1 \mathrm{~N}$ sodium hydroxide required to neutralize the acidity of $100 \mathrm{ml}$ of the sample. The volatile acid like acetic acid was determined by titrating $20 \mathrm{ml}$ of the alcohol distillate with $0.1 \mathrm{NaOH}$ solution, using phenolphthalein as an indicator. The volatile acidity of beers was expressed as $\mathrm{ml}$ of $0.1 \mathrm{~N}$ alkali required to neutralize the volatile acids contained in $100 \mathrm{ml}$ of beer. For the determination of dry matter, beers $(100 \mathrm{ml})$ previously calibrated, were evaporated in a capsule, firstly by heating in a water bath and then in an oven at $105^{\circ} \mathrm{C}$. Then, the capsule was reweighed, the increase provides the dry weight of $100 \mathrm{ml}$ of beers and the dry extract expressed in $\mathrm{g} / \mathrm{ml}$. To calculate the percent of ashes, $25 \mathrm{ml}$ of beers were evaporated in a platinum dish on a water bath, then cautiously carbonize the dry residue of a small flame; they were incinerated slowly to dark red and then weighed. The ashes weight was reported to $100 \mathrm{ml}$ of beer.

\subsection{Determination of Polyphenols Content}

Aliquots of each beer $(1 \mathrm{ml})$ were lyophilized and suspended in the same initial volume using PBS. The total polyphenol content was measured using the Folin-Ciocalteau's phenol reagent, according to the method of Singleton and Rossi [33]. Briefly, $10 \mu \mathrm{l}$ of each lyophilized beer were mixed in an aqueous solution with FCR (5\%), sodium carbonate (2\%) and incubated at room temperature in the dark for $2 \mathrm{~h}$. The samples absorbance was measured spectrophotometrically at $760 \mathrm{~nm}$. The results were expressed as equivalent of quercetin (EqQ). All measurements were carried out in triplicates.

\subsection{Cell Culture and Viability}

HL-60 cells, derived from a human promyelocytic leukemia [34], were cultured in RPMI medium, supplemented with $10 \% \mathrm{FBS}, 200 \mu \mathrm{M}$ L-glutamine, $5000 \mathrm{IU} / \mathrm{ml}$ penicillin and $5000 \mathrm{mg} / \mathrm{ml}$ streptomycin, at $37^{\circ} \mathrm{C}$ in a humidified atmosphere containing $5 \% \mathrm{CO}_{2}$. Cells were cultured at density of $2.5 \times 10^{5} / \mathrm{ml}$ in 48 multiwell plates and incubated for $48 \mathrm{~h}$ in a medium added with different amounts of lyophilized beers. Cell viability assay was performed using neutral red viability test as described [35]. Briefly, cells were incubated with neutral red solution, $0.066 \% \mathrm{v} / \mathrm{v}$ final concentration, for $3 \mathrm{~h}$ and then lysed using a buffer (50 mM Tris-HCl pH 7.4; $150 \mathrm{mM}$ $\mathrm{NaCl} ; 5 \mathrm{mM}$ dithiothreitol, and $1 \%$ Triton X-100) containing $1 \%$ acetic acid and $50 \%$ absolute ethanol. Absorbance was determined spectrophotometrically at $540 \mathrm{~nm}$. Microphotographs were made using an invertoscope
Axiovert 200M Zeiss (Zeiss, Arese, MI, Italy).

\subsection{Statistical Analysis}

Values are presented as means \pm standard deviation (SD). Differences in data reported in the present paper were determined by Student's t-test. Significance is indicated in figure legends.

\section{Results and Discussion}

Density (g/ml), alcoholic degree (\%), volatile acidity (ml $\mathrm{NaOH} / 100 \mathrm{ml})$, total acidity (ml NaOH/100ml), dry matter $(\mathrm{g} / 100 \mathrm{ml})$, ashes $(\mathrm{g} / \mathrm{ml})$ for the finished products are listed in Table 1. Values of density range between 0.9915 - 0.9969, lower than those found in commercial beers, usually greater than $1.0000 \mathrm{~g} / \mathrm{ml}$. Although beer density can be calculated very precisely, no reference values are available, since density (or specific gravity) depends by a number of different factors including temperature and moisture content of the ingredients. Even a slight change in one of these parameters is sufficient to alter the beer density which generally indicates the amount of water present, i.e., a beer with a higher percentage of water is expected to have a lower density.

The alcohol content of beers ranges from $4 \%$ to $12 \%$, with an average of $4 \%$ in regular beers. The alcoholic content in pilsner, lager, cider and stout beers are $3 \%$ $6 \%, 4 \%-5 \%, 4 \%-8 \%$ and $5 \%-10 \%$, respectively. Alcohol-free beer must have a alcohol content not exceeding $1 \%$. Samples tested in the present study show values higher than $4 \%$, except for sample 3 , similarly to Spanish beers [36] which show alcohol degree ranging between $1.31 \%-5.55 \%$. On the contrary, Belgian and Dutch beers present a higher alcoholic percentage, i.e., $5.02 \%-11.21 \%$ for blonde beers and $5.98 \%-11.9 \%$ for dark ones [37], while for beers from Belgium, Italy, Germany, Japan, The Netherlands, Czech Republic, Cuba, Mexico, Denmark and England, alcohol values range between $0.5 \%$ and $9.5 \%$ [38].

The acidity in beers is due to the presence of various organic acids (especially lactic acid), like acid phosphates, while high values of volatile acidity, expressed mainly as acetic acid, indicate beers stored in unfavorable conditions. With regard to total acidity, regular beers should not exceed $35 \mathrm{ml} \mathrm{N} / 10 \mathrm{NaOH} / 100 \mathrm{ml}$, while for special beers, values can increase to $40 \mathrm{ml} \mathrm{N} / 10 \mathrm{NaOH} /$ $100 \mathrm{ml}$. In stout, total acidity should not exceed $45 \mathrm{ml}$ $\mathrm{N} / 10 \mathrm{NaOH} / 100 \mathrm{ml}$. Values of volatile acidity for regular, special and stout beers should not exceed 7, 8.5 and 10 $\mathrm{ml} \mathrm{N} / 10 \mathrm{NaOH}$ per $100 \mathrm{ml}$, respectively. Total and volatile acidity for samples reported in Table 1 are below the maximum value expected for regular beers.

Ashes represent the inorganic residue remaining after removal of water and organic matter by heating in the 
Table 1. Physical-chemical features of selected beers.

\begin{tabular}{cccccccc}
\hline Beers & $\begin{array}{c}\text { Polyphenols } \\
(\boldsymbol{\mu M} \text { EqQ) }\end{array}$ & $\begin{array}{c}\text { Density } \\
(\mathbf{g} / \mathbf{m l})\end{array}$ & $\begin{array}{c}\text { Alcoholic } \\
\mathbf{( \% )}\end{array}$ & $\begin{array}{c}\text { Volatile Acidity } \\
(\mathbf{m l ~ N a O H / 1 0 0 m l})\end{array}$ & $\begin{array}{c}\text { Total Acidity } \\
(\mathbf{m l ~ N a O H / 1 0 0 m l )}\end{array}$ & $\begin{array}{c}\text { Dry Matter } \\
(\mathbf{g} / \mathbf{1 0 0 m L})\end{array}$ & $\begin{array}{c}\text { Ash } \\
(\mathbf{g} / \mathbf{m L})\end{array}$ \\
\hline $\mathbf{1}$ & $1612 \pm 22$ & $0.9927 \pm 0.1213$ & 5.13 & $2.5 \pm 0.3$ & $27.5 \pm 1.4$ & $4.372 \pm 0.731$ & $0.284 \pm 0.012$ \\
$\mathbf{2}$ & $1135 \pm 99$ & $0.9942 \pm 0.098$ & 4.30 & $1.5 \pm 0.7$ & $24.0 \pm 0.8$ & $3.644 \pm 0.326$ & $0.304 \pm 0.089$ \\
$\mathbf{3}$ & $690 \pm 25$ & $0.9969 \pm 0.1146$ & 2.11 & $1.0 \pm 0.6$ & $10.0 \pm 1.1$ & $2.492 \pm 0.269$ & $0.262 \pm 0.059$ \\
$\mathbf{4}$ & $2275 \pm 11$ & $0.9920 \pm 0.1210$ & 5.66 & $2.0 \pm 1.1$ & $18.0 \pm 1.2$ & $6.360 \pm 0.086$ & $0.278 \pm 0.037$ \\
$\mathbf{5}$ & $2402 \pm 17$ & $0.9915 \pm 0.0977$ & 5.99 & $2.0 \pm 0.9$ & $18.5 \pm 0.9$ & $6.780 \pm 0.054$ & $0.254 \pm 0.052$ \\
\hline
\end{tabular}

presence of oxidizing agents. They provide a measure of the total amount of minerals within a food. Samples tested in the present work show comparable ash values.

Table 1 also reports the total phenolic content of the beers measured by Folin-Ciocalteu method. In this study, alcohol was eliminated by lyophilization to avoid its cytotoxic effect. Polyphenols were measured before and after lyophilization without any significant difference (data not shown). Samples 4 and 5 resulted in higher total phenol content, 2275 and $2402 \mu \mathrm{M}$ EqQ, respectively, while sample 3 showed the lowest content ( $690 \mu \mathrm{M} \mathrm{EqQ).}$ The former samples also show dry matter values higher than the other beers tested, in agreement with the total phenolic content. This observation led us to hypothesize a more pronounced biological activity.

To assess the cytotoxic effect of the different lyophilized beers, we treated HL-60 cell line with same volumes of lyophilized samples solubilized in PBS (10 $\mu \mathrm{l}$ diluted 1:50 in the culture medium) for $48 \mathrm{~h}$ (Figure 1(a)). The beers number 4 and 5 induced a significant reduction in cell viability at (34\% and $40 \%$, respectively). The decrease in cell number caused by Sample 5 is clearly shown in the microphotograph reported in Figure 1(b). The remaining samples evidenced a lower cytotoxicity ranging between $15 \%-20 \%$. This result parallels with the values of total polyphenol concentrations reported in Table 1. Therefore, we hypothesized a cause-effect relationship between increased cytotoxicity and amount of phenolic compounds in the lyophilized samples. To verify this hypothesis, we treated HL-60 cells with equal amount of total polyphenols, normalized in terms of quercetin equivalents (45 nmoles EqQ; Figure 2). In this conditions, sample 3 , which possessed the lowest amount of polyphenols (Table 1), was to most effective in reducing cell viability (47\%). The remaining four samples showed a similar cytotoxic effect ranging between $30 \%$ $40 \%$ (Figure 2). These data suggest the presence in sample 3 of bioactive compounds not present in the other beers, or a higher relative concentration of the most antiproliferative molecules.

However, as showed in Figure 3(a), calculating the correlation index between cell viability and total content of phenols, we observed a negative correlation $(-0.806)$, confirming the importance of the qualitative profile of phenolic compounds and/or their relative concentrations

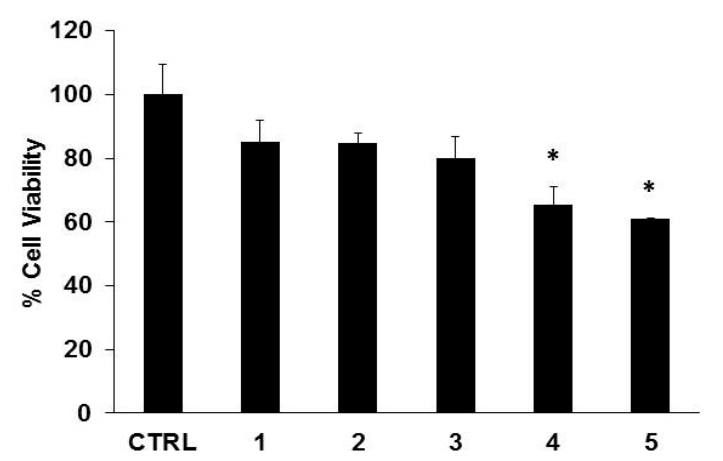

(a)

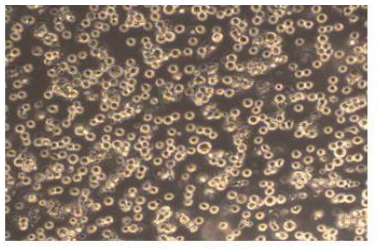

Untreated

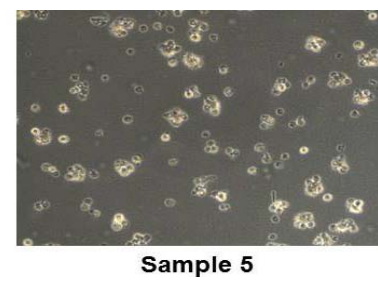

(b)
Figure 1. Lyophilized beers induce reduction in cell viability in HL-60 cells. Cells were treated for $48 \mathrm{~h}$ with the five lyophilized beers solubilized in PBS (Panel A). Values are presented as mean \pm S.D. compared to untreated cells. Symbols indicate significance: ${ }^{*} p<0.05$ respect to untreated cells. Panel B shows representative images of cells untreated (left) and treated (right) with sample 5 (optical microscope Axiovert 200M Zeiss; 100X, phase contrast).

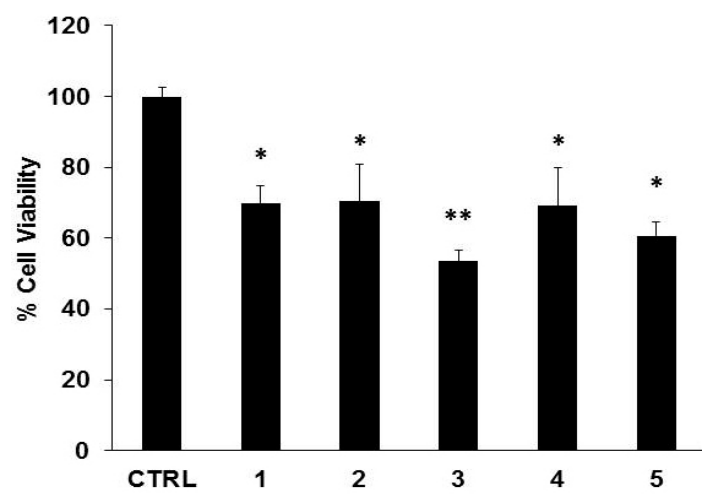

Figure 2. Lyophilized beers induce reduction in cell viability in HL-60 cells. Cells were treated for $48 \mathrm{~h}$ with 45 nmoles EqQ. Values are presented as mean \pm S.D. compared to untreated cells. Symbols indicate significance: ${ }^{*} p<0.01$ and ${ }^{* *} p<0.001$ respect to untreated cells. 


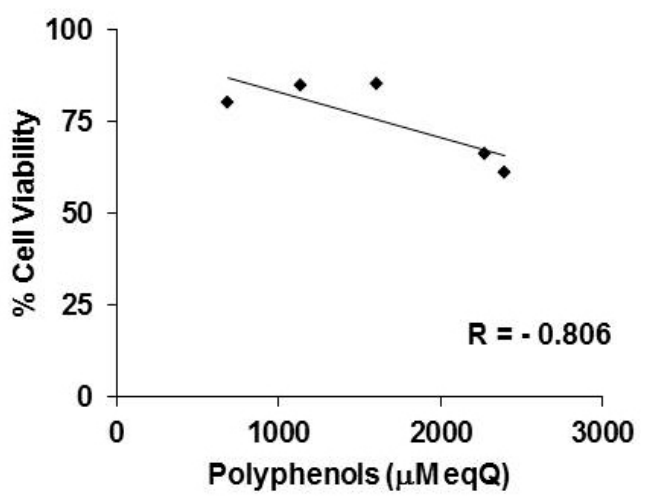

(a)

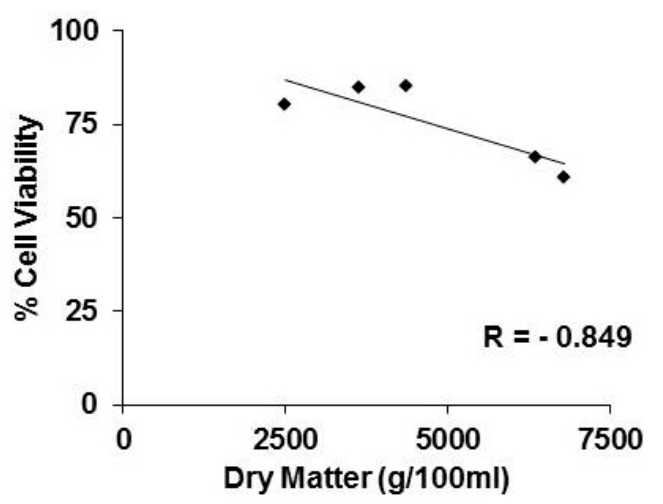

(b)

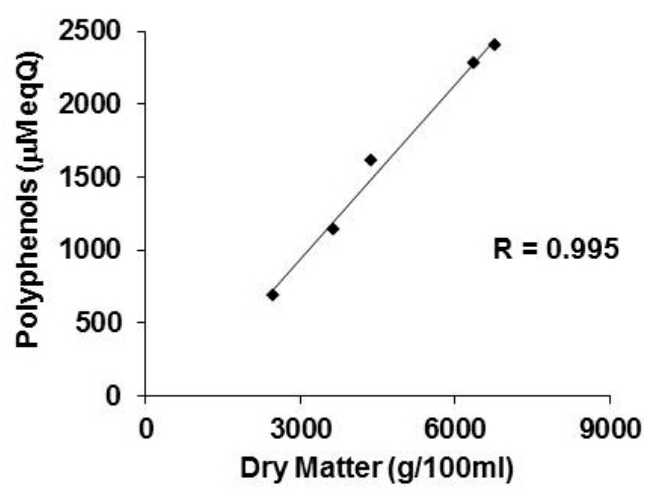

(c)

Figure 3. Correlation index. The correlation index was calculated between cell viability and polyphenols (a) cell viability and dry matter (b) and polyphenols and dry matter (c) of five commercial beers.

in the lyophilized samples. A negative correlation existed between cell viability and the dry matter $(-0.849)$, as mentioned above, and a higher positive correlation between polyphenol content and dry matter (0.995) (Figures 3(b) and (c)).

It is worthwhile to note that beers 4 and 5, which possessed the higher polyphenol content were obtained using hops and fermented by S. cerevisiae; thus, we hypothesize that the fermented hops strongly contributed to the higher polyphenol content of these beers. Sample 3, showing the lowest content of polyphenols, was also obtained from hops; however, in this case, yeasts employed, “abbazia”, were different from S. cerevisiae, suggesting that during fermentation the amount and the chemical nature of hop polyphenols significantly changes. This hypothesis supports data presented in Figure 2, where we showed that quality, e.g. chemical composition and relative concentrations, more than quantity, e.g. total amount of polyphenols, are key features in determining the antiproliferative activity of lyophilized beers.

In a previous paper, we demonstrated that a beer with a significantly high polyphenol content was cytotoxic with respect to a commercial beer with low polyphenol content on HL-60 cell line [24]. We extended this observation pointing out our attention on the concept that specific polyphenol composition is even more important than their total amount. These differences are related to the various origins of polyphenols in beers, since they can derive from hops or malts possessing phenolic profiles significantly different. In fact, in malt, catechin and prodelphinidin B3 are respectively the major monomeric and dimeric flavan-3-ols [39], while common hop ( $\mathrm{Hu}$ mulus lupulus) constitutes a source of numerous preny lated chalcones, such as xanthohumol and flavanones, such as 8-prenylnaringenin and isoxanthohumol [21]. Currently, we cannot attribute to a specific molecule or class of molecules the cytotoxicity measured on HL-60 cells. However, our findings suggest that acting on specific varieties of malts and hops and manipulating appropriately different strains of yeasts will be possible to obtain beers low in alcohol and high in polyphenols. These beverages may represent innovative functional products. Our efforts are directed to this aim with the support of biotechnologists in the brewing field.

In conclusion, we demonstrated that a commercial beer low in total polyphenol content can be more cytotoxic against malignant cell growth than beers with an higher content. This may depend by the presence of single molecule possessing high antiproliferative activity present in relatively high concentration or to a unique combination of several compounds present in low amount by acting synergistically. A future chemical characterization of phenolic compounds present in the most bioactive beers is mandatory to address this topic.

\section{Acknowledgements}

Beers employed in the present study were kindly provided by Mrs. Fabrizio and Federico Tarricone from the brewing company DRIVE Beer S.r.l. (Baragiano, Pz, Italy).

\section{REFERENCES}

[1] M. B. Sporn and N. Suh, "Chemoprevention: An Essen- 
tial Approach to Controlling Cancer," Nature Review Cancer, Vol. 2, No. 7, 2002, pp. 537-543.

http://dx.doi.org/10.1038/nrc844

[2] C. Spagnuolo, M. Russo, S. Bilotto, I. Tedesco, B. Laratta and G. L. Russo, "Dietary Polyphenols in Cancer Prevention: The Example of the Flavonoid Quercetin in Leukemia,” Annals of the New York Academy of Sciences, Vol. 1259, 2012, pp. 95-103.

[3] S. Bilotto, C. Spagnuolo, M. Russo, I. Tedesco, B. Laratta and G. L. Russo, "Dietary Phytochemicals in Chemoprevention of Cancer: An Update," Immunology, Endocrine \& Metabolic Agents in Medicinal Chemistry, Vol. 13, 2013, pp. 2-24.

[4] T. Norat, D. Aune, D. Chan and D. Romaguera, "Fruits and Vegetables: Updating the Epidemiologic Evidence for the Wcrf/Aicr Lifestyle Recommendations for Cancer Prevention,” Cancer Treatment Research, Vol. 159, 2014, pp. 35-50.

[5] M. Russo, C. Spagnuolo, I. Tedesco, S. Bilotto and G. L. Russo, "The Flavonoid Quercetin in Disease Prevention and Therapy: Facts and Fancies," Biochemical Pharmacology, Vol. 83, No. 1, 2012, pp. 6-15. http://dx.doi.org/10.1016/j.bcp.2011.08.010

[6] C. J. Weng and G. C. Yen, "Flavonoids, a Ubiquitous Dietary Phenolic Subclass, Exert Extensive in Vitro AntiInvasive and in Vivo Anti-Metastatic Activities," Cancer Metastasis Review, Vol. 31, No. 1-2, 2012, pp. 323-351. http://dx.doi.org/10.1007/s10555-012-9347-y

[7] M. Gonzalez-Vallinas, M. Gonzalez-Castejon, A. Rodriguez-Casado and A. Ramirez de Molina, "Dietary Phytochemicals in Cancer Prevention and Therapy: A Complementary Approach with Promising Perspectives," $\mathrm{Nu}$ trition Reviews, Vol. 71, No. 9, 2013, pp. 585-599. http://dx.doi.org/10.1111/nure.12051

[8] M. Russo, C. Spagnuolo, I. Tedesco and G. L. Russo, "Phytochemicals in Cancer Prevention and Therapy: Truth or Dare?” Toxins (Basel), Vol. 2, No. 4, 2010, pp. 517-551. http://dx.doi.org/10.3390/toxins2040517

[9] H. J. Forman, K. J. Davies and F. Ursini, "How Do Nutritional Antioxidants Really Work: Nucleophilic Tone and Para-Hormesis Versus Free Radical Scavenging in Vivo," Free Radical Biology \& Medicine, Vol. 66, 2014, pp. 24-35. http://dx.doi.org/10.1016/j.freeradbiomed.2013.05.045

[10] B. Halliwell, "Free Radicals and Antioxidants: Updating a Personal View," Nutrition Reviews, Vol. 70, No. 5, 2012, pp. 257-265. http://dx.doi.org/10.1111/j.1753-4887.2012.00476.x

[11] G. L. Russo, M. Russo, C. Spagnuolo, I. Tedesco, S. Bilotto, R. Iannitti and R. Palumbo, "Quercetin: A Pleiotropic Kinase Inhibitor against Cancer,” Cancer Treatment Research, Vol. 159, 2014, pp. 185-205.

[12] D. E. Brash and P. A. Havre, "New Careers for Antioxidants," Proceedings of the National Academy of Sciences of the United States of America, Vol. 99, No. 22, 2002, pp. 13969-13971. http://dx.doi.org/10.1073/pnas.232574399

[13] M. Nelson, “The Barbarian's Beverage: A History of Beer in Ancient Europe,” Routledge, Abingdon, 2005, p. 1.
[14] V. C. Preedy, "Beer in Health and Disease Prevention," Elsevier Inc., Academic Press, San Diego, 2009.

[15] S. Arranz, G. Chiva-Blanch, P. Valderas-Martinez, A. Medina-Remon, R. M. Lamuela-Raventos and R. Estruch, "Wine, Beer, Alcohol and Polyphenols on Cardiovascular Disease and Cancer,” Nutrients, Vol. 4, No. 7, 2012, pp. 759781. http://dx.doi.org/10.3390/nu4070759

[16] C. Chao, "Associations between Beer, Wine, and Liquor Consumption and Lung Cancer Risk: A Meta-Analysis,” Cancer Epidemiology, Biomarkers \& Prevention, Vol. 16, No. 11, 2007, pp. 2436-2447. http://dx.doi.org/10.1158/1055-9965.EPI-07-0386

[17] S. Costanzo, A. Di Castelnuovo, M. B. Donati, L. Iacoviello and G. de Gaetano, "Wine, Beer or Spirit Drinking in Relation to Fatal and Non-Fatal Cardiovascular Events: A Meta-Analysis," European Journal of Epidemiology, Vol. 26, No. 11, 2011, pp. 833-850. http://dx.doi.org/10.1007/s10654-011-9631-0

[18] V. Valls-Belles, C. Torres, P. Muniz and P. CodonerFranch, "Effect of Beer Consumption on Levels of Complex I and Complex Iv Liver and Heart Mitochondrial Enzymes and Coenzymes Q9 and Q10 in AdriamycinTreated Rats,” European Journal Nutrition, Vol. 49, No. 3, 2010, pp. 181-187. http://dx.doi.org/10.1007/s00394-009-0064-4

[19] G. Vilahur, L. Casani, J. M. Guerra and L. Badimon, “Intake of Fermented Beverages Protect against Acute Myocardial Injury: Target Organ Cardiac Effects and Vasculoprotective Effects," Basic Research Cardiology, Vol. 107, No. 5, 2012, p. 291. http://dx.doi.org/10.1007/s00395-012-0291-3

[20] H. Nozawa, A. Yoshida, O. Tajima, M. Katayama, H. Sonobe, K. Wakabayashi and K. Kondo, "Intake of Beer Inhibits Azoxymethane-Induced Colonic Carcinogenesis in Male Fischer 344 Rats,” International Journal of Cancer, Vol. 108, No. 3, 2004, pp. 404-411.

http://dx.doi.org/10.1002/ijc.11541

[21] C. Gerhauser, "Beer Constituents as Potential Cancer Chemopreventive Agents,” European Journal Cancer, Vol. 41, No. 13, 2005, pp. 1941-1954. http://dx.doi.org/10.1016/j.ejca.2005.04.012

[22] G. Iacomino, I. Tedesco and G. L. Russo, "Biological Properties of Beer and Its Components Compared to Wine,” In: V. R. Preddy, Ed., Beer in Health and Disease Prevention, Elsevier Inc., Academic Press, San Diego, 2009, pp. 483-490. http://dx.doi.org/10.1016/B978-0-12-373891-2.00047-X

[23] P. J. Magalhaes, D. O. Carvalho, J. M. Cruz, L. F. Guido and A. A. Barros, "Fundamentals and Health Benefits of Xanthohumol, a Natural Product Derived from Hops and Beer," Natural Product Communications, Vol. 4, No. 5, 2009, pp. 591-610.

[24] I. Tedesco, A. Nappo, F. Petitto, G. Iacomino, F. Nazzaro, R. Palumbo and G. L. Russo, “Antioxidant and Cytotoxic Properties of Lyophilized Beer Extracts on Hl-60 Cell Line,” Nutrution \& Cancer, Vol. 52, No. 1, 2005, pp. 7483. http://dx.doi.org/10.1207/s15327914nc5201_10

[25] J. F. Stevens, A. W. Taylor, J. E. Clawson and M. L. Deinzer, "Fate of Xanthohumol and Related Prenylfla- 
vonoids from Hops to Beer,” Journal of Agricultural and Food Chemistry, Vol. 47, No. 6, 1999, pp. 2421-2428. http://dx.doi.org/10.1021/jf990101k

[26] H. Hirata, Yimin, S. Segawa, M. Ozaki, N. Kobayashi, T. Shigyo and H. Chiba, "Xanthohumol Prevents Atherosclerosis by Reducing Arterial Cholesterol Content via Cetp and Apolipoprotein E in Cetp-Transgenic Mice,” PLoS One, Vol. 7, No. 11, 2012, Article ID: e49415. http://dx.doi.org/10.1371/journal.pone.0049415

[27] S. Kapoor, "Xanthohumol and It's Emerging Anti-Neoplastic Effects: Beyond It's Role in Breast Carcinomas,” Molecular Nutrition \& Food Research, Vol. 56, No. 12, 2012, p. 1760. http://dx.doi.org/10.1002/mnfr.201270105

[28] I. Zajc, M. Filipic and T. T. Lah, "Xanthohumol Induces Different Cytotoxicity and Apoptotic Pathways in Malignant and Normal Astrocytes," Phytotherapy Research, Vol. 26, No. 11, 2012, pp. 1709-1713. http://dx.doi.org/10.1002/ptr.4636

[29] J. Plazar, B. Zegura, T. T. Lah and M. Filipic, "Protective Effects of Xanthohumol against the Genotoxicity of Benzo(a)Pyrene (Bap), 2-Amino-3-Methylimidazo[4,5-F] Quinoline (Iq) and Tert-Butyl Hydroperoxide (T-Booh) in Hepg2 Human Hepatoma Cells,” Mutation Research, Vol. 632, No. 1-2, 2007, pp. 1-8. http://dx.doi.org/10.1016/j.mrgentox.2007.03.013

[30] K. B. Harikumar, A. B. Kunnumakkara, K. S. Ahn, P. Anand, S. Krishnan, S. Guha and B. B. Aggarwal, "Modification of the Cysteine Residues in Ikappabalpha Kinase and Nf-Kappab (P65) by Xanthohumol Leads to Suppression of Nf-Kappab-Regulated Gene Products and Potentiation of Apoptosis in Leukemia Cells,” Blood, Vol. 113, No. 9, 2009, pp. 2003-2013. http://dx.doi.org/10.1182/blood-2008-04-151944

[31] T. L. Yen, C. K. Hsu, W. J. Lu, C. Y. Hsieh, G. Hsiao, D. S. Chou, G. J. Wu and J. R. Sheu, "Neuroprotective Effects of Xanthohumol, a Prenylated Flavonoid from Hops (Humulus Lupulus), in Ischemic Stroke of Rats,” Journal of Agricultural and Food Chemistry, Vol. 60, No. 8, 2012, pp. 1937-1944. http://dx.doi.org/10.1021/jf204909p

[32] H. Nozawa, W. Nakao, F. Zhao and K. Kondo, "Dietary Supplement of Isohumulones Inhibits the Formation of Aberrant Crypt Foci with a Concomitant Decrease in Pro- staglandin E2 Level in Rat Colon,” Molecular Nutrition \& Food Research, Vol. 49, No. 8, 2005, pp. 772-778. http://dx.doi.org/10.1002/mnfr.200500027

[33] V. L. Singleton and J. A. Rossi Jr., “Colorimetry of Total Phenolics with 726 Phosphomolybdic-Phosphotungstic Acid Reagents," American Journal of Enology and Viticulture, Vol. 16, 1965, pp. 144-158.

[34] R. Gallagher, S. Collins, J. Trujillo, K. McCredie, M. Ahearn, S. Tsai, R. Metzgar, G. Aulakh, R. Ting, F. Ruscetti and R. Gallo, "Characterization of the Continuous, Differentiating Myeloid Cell Line (Hl-60) from a Patient with Acute Promyelocytic Leukemia,” Blood, Vol. 54, No. 3, 1979, pp. 713-733.

[35] M. Russo, R. Palumbo, A. Mupo, M. Tosto, G. Iacomino, A. Scognamiglio, I. Tedesco, G. Galano and G. L. Russo, "Flavonoid Quercetin Sensitizes a Cd95-Resistant Cell Line to Apoptosis by Activating Protein Kinase Calpha," Oncogene, Vol. 22, No. 21, 2003, pp. 3330-3342. http://dx.doi.org/10.1038/sj.onc.1206493

[36] F. A. Inon, S. Garrigues and M. de la Guardia, “Combination of Mid- and Near-Infrared Spectroscopy for the Determination of the Quality Properties of Beers," Analytica Chimica Acta, Vol. 571, No. 2, 2006, pp. 167-174. http://dx.doi.org/10.1016/j.aca.2006.04.070

[37] E. Polshin, A. Rudnitskaya, D. Kirsanov, A. Legin, D. Saison, F. Delvaux, F. R. Delvaux, B. M. Nicolai and J. Lammertyn, "Electronic Tongue as a Screening Tool for Rapid Analysis of Beer,” Talanta, Vol. 81, No. 1-2, 2010 , pp. 88-94. http://dx.doi.org/10.1016/j.talanta.2009.11.041

[38] A. G. Mignani, L. Ciaccheri, A. A. Mencaglia, H. Ottevaere, E. E. S. Baca and H. Thienpont, "Optical Measurements and Patternrecognition Techniques for Identifying the Characteristics of Beer and Distinguishing Belgian Beers," Sensors and Actuators B: Chemical, Vol. 179, 2013, pp. 140-149.

[39] M. Dvorakova, M. M. Moreira, P. Dostalek, Z. Skulilova, L. F. Guido and A. A. Barros, "Characterization of Monomeric and Oligomeric Flavan-3-Ols from Barley and Malt by Liquid Chromatography-Ultraviolet DetectionElectrospray Ionization Mass Spectrometry,” Journal of Chromatography A, Vol. 1189, No. 1-2, 2008, pp. 398405. http://dx.doi.org/10.1016/j.chroma.2007.10.080

\section{Abbreviations}

EqQ: equivalents of quercetin;

PBS: phosphate-buffered saline;

FBS: fetal bovine serum;

FCR: Folin-Ciocalteau's phenol reagent;

SD: standard deviation;

R: coefficient correlation. 